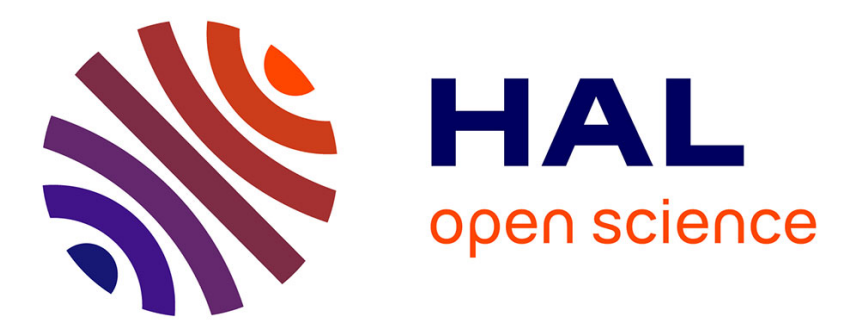

\title{
Comparison of two small group learning methods in 12th grade physics classes focusing on intrinsic motivation and academic performance
}

Roland Berger, Martin Hänze

\section{- To cite this version:}

Roland Berger, Martin Hänze. Comparison of two small group learning methods in 12th grade physics classes focusing on intrinsic motivation and academic performance. International Journal of Science Education, 2009, 31 (11), pp.1511-1527. 10.1080/09500690802116289 . hal-00516233

\section{HAL Id: hal-00516233 \\ https://hal.science/hal-00516233}

Submitted on 9 Sep 2010

HAL is a multi-disciplinary open access archive for the deposit and dissemination of scientific research documents, whether they are published or not. The documents may come from teaching and research institutions in France or abroad, or from public or private research centers.
L'archive ouverte pluridisciplinaire HAL, est destinée au dépôt et à la diffusion de documents scientifiques de niveau recherche, publiés ou non, émanant des établissements d'enseignement et de recherche français ou étrangers, des laboratoires publics ou privés. 


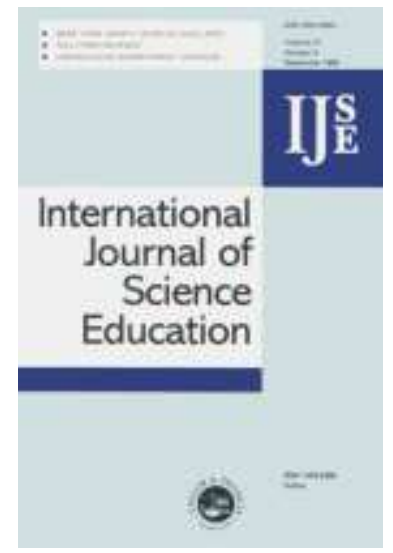

Comparison of two small group learning methods in 12th grade physics classes focusing on intrinsic motivation and academic performance

\begin{tabular}{|r|l|}
\hline Journal: & International Journal of Science Education \\
\hline Manuscript ID: & TSED-2007-0070.R1 \\
\hline Manuscript Type: & Research Paper \\
\hline Keywords: & $\begin{array}{l}\text { cooperative learning, experimental study, quantitative research, } \\
\text { physics education, classroom }\end{array}$ \\
\hline Keywords (user): & jigsaw classroom, intrinsic motivation, basic needs \\
\hline \multicolumn{2}{|l}{} \\
\hline
\end{tabular}

\section{S) ScholaroNE \\ Manuscript Central}




\section{Abstract}

Twelfth grade physics classes with 344 students participated in a quasiexperimental study comparing two small-group learning settings. In the jigsaw classroom, in contrast to the cyclical rotation method, teaching expectancy as well as resource interdependence is established. The study is based on the selfdetermination theory of motivation which states that the satisfaction of the 'basic needs' for experiencing autonomy, competence, and social relatedness is essential to promote intrinsic motivation. Regarding the experience of competence, a small effect in favour of the jigsaw classroom was found, whereas students in the cyclical rotation setting showed medium-sized benefits in experiencing autonomy. A path analysis revealed that these opposing effects balanced each other, that is, no effect from small-group method to intrinsic motivation was found.

In contrary to the motivational variables, achievement effects depended on the underlying study topic: based on scanning electron microscopy, the cyclical rotation setting outperformed jigsaw classroom, whereas an opposed trend is observed with regard to the microwave oven learning unit. The higher interestingness of the latter learning unit was revealed as a weak mediator from study topic to academic achievement. 


\section{Introduction}

Research on the effects of cooperative learning indicates that the learning process and the subsequent outcomes are strongly fostered by cooperative learning methods (Slavin , Hurley \& Chamberlain, 2003). As shown in the metaanalysis conducted by Springer, Stanne \& Donovan (1999) cooperative methods can be established with success in science, mathematics, and technology. Almost all of the studies included in this meta-analysis compared various forms of cooperative learning to more traditional methods. Relative little research has investigated in comparing two (ore more) small-group learning procedures. Research in this field should gain insight into various strengths as well as weaknesses of the different forms of small-group learning settings. In this paper we focus on the comparison of two forms of small-group learning: the jigsaw classroom and the cyclical rotation method. The jigsaw learning technique was first developed and implemented by Elliot Aronson (1978 \& 2002) in the 1970's. In the jigsaw classroom, the lesson is divided into segments. Students meet first with other students who have been assigned the same segment in an 'expert group'. Together, they research their segment, discuss, and clear up questions. The students then leave their groups to join 'jigsaw groups'. Each student in each group teaches the whole group about his or her expert subtopic, thus covering the whole topic. By contrast, in the cyclical rotation method the groups' composition is not varied while 'rotating' from subtopic to subtopic. Both methods differ mainly with respect to two aspects. First, in contrast to the cyclical rotation groups, the learners in the expert groups are aware of the demand 
to teach their peers in the jigsaw group ('teaching expectancy', Renkl, 1995) and they subsequently teach each other. Second, due to the task-specialisation in the jigsaw setting, each group member is accountable for a unique part of the activity and the students in the jigsaw groups are dependent on their experts' knowledge. In contrast, the cyclical rotation groups have access to the whole material and work together without separate responsibilities. Thus, 'resource interdependence' is established in the jigsaw condition (Slavin, Hurley \& Chamberlain, 2003). Most researchers in cooperative learning agree that individual accountability as well as positive interdependence are essential for fruitful cooperative working (Antil, Jenkins \& Wayne, 1998). The most striking differences between both methods are resumed in Table 1.

[Insert Table 1 about here]

We focus on the question if these characteristic differences lead to different outcomes with respect to academic performance and intrinsic motivation. It is widely believed that the jigsaw method supports intrinsic motivation (Hidi, Weiss, Berndorff, \& Nolan, 1998). But it is not clear why, and the question arises, if other forms of small-group learning like the cyclical rotation method lead to the same motivational benefits. In order to shed some light on this issue we refer to the self-determination theory by Deci and Ryan (2000). 


\section{Framework}

Self-determination theory

The self-determination theory postulates that innate basic psychological needs play an essential role for the development and maintenance of intrinsic motivation. The authors identified three needs for competence, autonomy, and social relatedness. They emphasize that intrinsic motivation requires satisfaction of perceived competence as well as autonomy. Following Deci and Ryan all three needs are necessary for intrinsic motivation, albeit the relatedness plays a role primarily in the maintenance of intrinsic motivation. The asserted impact of the relatedness for intrinsic motivation is controverted by Vallerand (2000). He points out that the perception of relatedness has a low relationship with self-determined motivation due to the individualistic type of classroom activities.

A frequently espoused position is that autonomy and social relatedness are incompatible or competing aspects of experience. In contrast, Deci and Ryan strongly emphasize that the need for autonomy refers to the desire to self-organize experience and behaviour and should not be interpreted as detachment or independence. That is, there is no incompatibility with relatedness.

Furthermore in the self-determination theory extrinsic motivation is no static concept, but supports for relatedness, autonomy, and competence allow the person to transform extrinsic motivation into a more self-determined motivation (Ryan \& Deci, 2000). The authors identified factors which foster an increasing identification with an object, e.g. its meaningfulness. With respect to the genesis 
of interest, the basic needs are important because they provide emotional feedback and thus contribute to the development of preferences (Krapp, 2002).

\section{Cooperative Learning and Jigsaw}

From a theoretical point of view there is no unifying approach that could explain all the outcomes of cooperative learning consistently (Slavin et al., 2003). Nevertheless all theoretical perspectives expect benefits of cooperative learning with respect to academic achievement compared to more traditional whole-class teaching methods, e.g. frontal teaching. An impressive research effort across a range of curriculum areas (in mathematics, science, and technology documented by a meta-analysis conducted by Springer et al. (1999)) supports this assertion, albeit not all studies agree.

Placing students in small groups and telling them to work together will not necessarily promote cooperation. The potential of learning together is maximized when students realize that they can not succeed unless they facilitate each other's learning (Gillies, 2003). Thus, unwanted side effects as ‘free-riding’ (a group member leaves it to the others to complete the task) and 'sucking' (a more active student lowers his effort because of the feeling that others are free-riding) should be suppressed. The question arises which conditions are crucial for positive outcomes of learning in small groups. Although this matter is still under active debate (Huber, 2003), there is consensus among most of the researchers, that two conditions are indispensable: positive interdependence and individual accountability (Antil et al., 1998). 
In the jigsaw classroom, positive interdependence is established through task specialization: the peers depend on the experts knowledge to be successful (resource interdependence). In contrast, all members of a cyclical rotation learning group work together without separate tasks. The positive impact of resource interdependence on achievement is not evident from the research literature (Slavin et al., 2003; Buchs, Butera \& Mugny, (2004)). In their study Buchs et al. found that resource interdependence outperformed working on identical material only if the difficulty of the information matches well to the students' level of competence. Otherwise peer teaching might be detrimental for the learning process due to reduced quality of explanations, which does not allow the listener to understand and master the information.

One of the main purposes of cooperative learning is individual mastery of the learning material. This is fostered by an individual accountability which exists when the individual performance of students is assessed. This prevents the group from doing the whole work by one or two students.

In the jigsaw classroom the students realize that they have to teach their peers, that is, they are responsible for their groups success. From a motivational point of view this teaching expectancy might facilitate intrinsic motivation, based on the need to have a meaningful impact on one's own environment (Benware \& Deci, 1984). On the other hand, teaching expectancy might lead to anxiety, thus deteriorating motivation and performance.

Regarding the impact of teaching expectancy on the experts cognitive structure, he or she is probably less likely to skip impasses in understanding and thus 
assigning more time to elaborate the material in the expert group. Additionally, explaining to someone else is expected to be one of the most effective means of elaboration (Slavin et al., 2003). Hence, from teaching expectancy and later teaching one would assume positive impact on achievement. According to this, Benware \& Deci found a stronger cognitive involvement under teaching expectancy. Nevertheless, Renkl (1995) reports no positive effect of the teaching expectancy on performance.

Simons (1997) highlights that autonomy for decision making is crucial for active learning. In comparison to frontal teaching the jigsaw classroom as well as cyclical rotation learning are characterized by more room to control the own learning process, that is, e.g. to adapt the learning speed to the task and to take task-related support. Nevertheless there are differences with respect to autonomy: the cyclical rotation method allows the scope to access the whole learning material whereas the students in a jigsaw group depend on the other experts. Regarding the structure of the two methods, in the jigsaw classroom there are certain inherent demands, e.g. the composition of new groups and the clearly defined division into two separate phases (expert and jigsaw groups). This might lead to a detrimental experience of autonomy.

\section{The lessons}

The study is based on two learning units, which were selected by the following criteria: the topics had to be meaningful, that is, important for the 12th grade level, as well as interesting. Furthermore it had to be possible to divide the 
material into independent segments, and the degree of difficulty had to be adapted to the students capabilities.

Following Häussler (1987), boys as well as girls of all ages from 11 to 16 have a higher than average interest in the context 'Physics as a vehicle to understand technical objects in everyday life' and the topic 'Structure of matter'. Thus, gaining insight into the microworld by suitable apparatuses seems to be a favourable topic for a multitude of students. From these interests it was suggested to take the topics 'Physics of the microwave oven' and 'Principles of the scanning electron microscope' as learning units. These topics are particular favourable for teaching physics in the 12th grade level, since the underlying physical principles cover two main areas of the curriculum: the generation and propagation of electromagnetic waves as well as the motion of charged particles in electric and magnetic fields. For gaining a useful insight into these topics, we give a concise survey of both.

\section{Principles of the Scanning Electron Microscope}

Free electrons are accelerated by a high voltage towards the sample. When the electron beam hits the sample further electrons are released from its surface. The so called Everhart-Thornley detector collects these secondary electrons. The brightness of the corresponding pixel on the computer screen is controlled by the number of electrons collected by the detector per second. To capture the whole sample the electron beam is scanned by the magnetic field of current-carrying coils. The learning unit consists of these basic information about the components 
of the microscope and its scanning principle. Further the release of secondary electrons due to the interaction of the electron beam with the sample is discussed. In the group work the following four subtopics are discussed:

- The generation of the electron beam by acceleration of free electrons in the electron gun.

- The force on the electron beam due to the magnetic field of the coils, that is the Lorentz-force.

- The question, how the penetration depth into the sample depends on the energy of the electron beam and the atomic number of the sample material.

- $\quad$ The working principle of the Everhart-Thornley detector.

Additionally, in higher performing classes the physics of the electron lense might be incorporated as a further subtopic. The electron microscope can be used to teach some important advanced physics: the electron beam generates $\mathrm{x}$-rays when penetrating the sample. In order to highlight specific elements in the picture the characteristic lines from the spectrum are captured by an x-ray detector. With respect to quantum physics, the resolution of the electron microscope is ultimately limited by the de Broglie wavelength of the incident electrons. Since these topics are not covered by the current 12th class curriculum in Germany they were not included into the learning unit.

We recommend the excellent book of Goldstein et al. (1992) providing further information on physics and technology of the scanning electron microscope. 
Physics of the microwave oven

Microwaves can heat matter only if its molecules have a permanent electric dipole moment. Due to the interaction of the electric field of the electromagnetic wave with the dipole moment of the water molecule, rotational motion is excited. The increase in motional energy is macroscopically linked to an increase of the liquids temperature. As most food has an appreciable water content, microwaves can heat most of the common food, e.g. meat and vegetables.

On this basis, the following four questions are discussed in the groups:

- Why does the metallic grid in the ovens front door transmit visible light, but reflects microwaves? As a rule of thumb, the ratio of the wavelength to the diameter of the holes is the key factor.

- For what reason the turntable rotates inside the microwave oven? Due to the reflection of electromagnetic waves at the metallic walls inside the cooking chamber, a standing wave is generated. Without rotation, the food thus is not heated by the microwaves in the nodes of the standing microwave, what leads to a non-uniform temperature pattern.

- How is the high frequency microwave generated? In the so called magnetron, suitable resonant circuits are excited which emit microwave radiation.

- Is a microwave oven an energy saving device? This question is investigated by comparing the input electric power and the deposited thermal energy when heating water. 


\section{Cooperation script}

To foster the interaction with the learning material we adapted a cooperation script, first proposed by Dansereau (1988) for dyadic cooperation. MURDER is an acronym for the sequence of various phases in cooperation: after the Mood-Phase to establish a positive mind-set for learning, the students studied their expert topic to understand the main ideas and facts. Subsequently, the experts recalled their segment while teaching their jigsaw groups. Afterwards they asked their peers to answer questions for repetition and comprehension, in order to detect problems and elaborate the topic’s content and structure. In the concluding Review-Phase the peer students were requested to determine the most relevant keywords relating to the segment they were taught about. In order to match both conditions, the students in the cyclical rotation setting were demanded to answer repetition and comprehension questions and to formulate keywords as well as in the jigsaw classroom.

The learning material provided to the students in order to perform their tasks and to prepare for the test can be downloaded from our homepage ${ }^{1}$.

\footnotetext{
${ }^{1}$ Microwave oven: http://www.physik.uni-osnabrueck.de/didaktik/mikrowelle.htm; Scanning electron microscope: http://www.physik.uni-osnabrueck.de/didaktik/rem.htm (in German)
} 


\section{The study \\ Hypothesis}

\section{Basic needs and intrinsic motivation}

The students in the expert groups are aware that they have to teach the material to their peers in the jigsaw groups. This teaching expectancy thus should foster an active, deep level interaction with the learning material. Moreover, the student's experience of responsibility for a segment of the material, and of acting as an expert source for other students, is posited to give the student a feeling of competence. In preceding studies, we found that the degree of difficulty of our learning units is well adapted to the students capabilities. Furthermore, there is no anxiety which degrades the learning process, since the students know each other well. In summary, in the jigsaw condition we expect a higher experience of competence as compared to the cyclical rotation setting (Hypothesis $1 \mathrm{a}$ ).

Students in the cyclical rotation condition have more leeway in structuring the learning process, since there is no defined time span to interact with a single subtopic. The learning speed can be adjusted by the students in a more appropriate way than in the jigsaw condition. Thus, the students should feel themselves more free, that is, we expect a higher autonomy as compared to the jigsaw condition (Hypothesis $1 \mathrm{~b}$ ).

In our study, the composition of experts groups as well as cyclical rotation groups was determined by students' self-selection. Thus, in the expert groups as well as 
in the station to station groups, the students should feel good with their peers. Due to the inherently similar social structure of both methods we expect no difference between both conditions regarding the experience of social relatedness (Hypothesis 1 c).

If these hypotheses are confirmed, we expect no difference in intrinsic motivation (Hypothesis 2), since, following the self-determination theory, the feeling of competence as well as the feeling of autonomy must both be enhanced simultaneously by one of the methods to foster intrinsic motivation.

\section{Academic Performance}

Regarding the academic performance, two opposite effects might come into play:

- We expect advantages on the students' assigned 'expert' segments of knowledge in comparison with the cyclical rotation learning. The teaching expectancy in the experts group, associated with an intensive interaction with the learning material, as well as the subsequent giving of explanations in the jigsaw groups, should improve the cognitive structure of the instructing student (Springer et al., 1999).

- Concerning the segments that the students learned about from fellow group members, losses due to reduced information transmission might appear. When comparing the jigsaw method to frontal teaching this detrimental effect was apparent (Hänze \& Berger, 2007). 
Thus, regarding the overall performance it is not clear which of these both factors dominates. For that reason we do not formulate a hypothesis concerning the academic performance.

\section{Participants, experimental design and procedure}

20 physics classes (12th grade level), with a total of 286 students, participated in the study in the 2003-2004 school year. Originally, the study was to be conducted as a cross-over design that investigated the method of instruction as both between-subject factor and within-subject factor, although with different study topics (Figure 1). Nine classes (Group A) studied the topic 'scanning electron microscope' in the jigsaw classroom and then were taught the second study topic, 'microwave oven' in the cyclical rotation method. 11 classes (Group B) learned about the first study topic through cyclical rotation teaching and then studied the physics of the microwave oven through the jigsaw classroom.

[Insert Figure 1 about here]

However, for the second study topic (microwave oven) about a half year later, seven classes as well as some students from the remaining classes dropped out from our study (a total of 121 students). In order to compensate for this, four new classes of 12th graders (58 students) were included. That is, 223 students were available for the second study topic. The design was evaluated as a betweensubjects design for the method of instruction with the study topic as a control 
factor. Classes were assigned randomly to the jigsaw classroom or the cyclical rotation learning condition.

First, students were given a test of academic performance (pretest). The actual learning unit was made up of four school hours (scanning electron microscope) and three school hours (microwave oven), respectively (see Figure 1). Basic information on the topics was introduced in two (scanning electron microscope) and one (microwave oven) physics hours through direct instruction (same for both methods of instruction). At the end of these lessons, the learning experience questionnaire was given as a pretest measurement. In the following double period students in the experimental groups worked in the jigsaw classroom, while the other groups studied the same learning material through the cyclical rotation method. In the jigsaw classroom, the learning experience questionnaire was administered after the work in the expert groups and again when students had finished with the jigsaw groups. In the cyclical rotation condition, the learning experience questionnaire was given once at the end of the lesson.

For comparison with the cyclical rotation condition, the chosen point in time of measurement of the learning experience variables is after working in the expert groups. We did not contrast the cyclical rotation groups with jigsaw groups, since the main focus of the latter lies on the peer teaching process.

The posttest on academic performance was given in an extra lesson some days after the learning unit. 


\section{Instruments and measures}

\section{Learning experience questionnaire}

On the basis of known scales (Prenzel et al., 1993, 2001) we developed a new questionnaire for the following reasons:

- The questionnaire was administered at several points in time. In order not to overstrain the students, the questionnaire needed to be short.

- The items had to be applicable for different learning situations (direct instruction as well as group work).

In the present study, the following scales were used in the german version (cf. Berger \& Hänze, 2004). The Cronbach alpha internal consistency reliability for each of the subscales, measured after working in the expert groups and cyclical rotation condition, respectively, is shown in brackets:

Social relatedness $(\alpha=.69)$

SR 1: The atmosphere was pleasant.

SR 2: I felt comfortable with my group.

Experience of competence $(\alpha=.84)$

C 1:I noticed that I really understood things.

C 2: I felt able to master the work.

Experience of autonomy $(\alpha=.54)$

A 1: I had the opportunity to learn about new things on my own. 
A 2: I had a feeling of freedom to make some of my own decisions.

Intrinsic motivation $(\alpha=.69)$

IM 1: I was eager to learn about the material.

IM 2: The work was really fun.

IM 3: I didn't notice how the time flew by.

Students respond to the items by using a 5-point, Likert-type scale in which only the first and fifth points are anchored ('strongly disagree' to ‘strongly agree').

Additionally, the factor loadings of the basic need items are shown in Table 2. We obtained a clear and interpretable structure of the basic needs items. The extraction is based on a principal component analysis with varimax rotation and three factors, explaining $77.1 \%$ of the variance.

\section{[Insert Table 2 about here]}

\section{Academic performance tests}

The pre- and post performance tests differ from each other, since topic specific questions were included in the posttest. The classification of the test questions (reproduction, reorganisation, and transfer) for each of the topics are up to german school standards set by ministry of education (Leisen, 2004). The tests correlate to the last grade earned in physics to .42 and .45 , respectively. The reliabilities of the 
tests are $\alpha=.45$ and .60 , respectively. In consideration of the fact that the four test items refer to four different subtopics, these values seem to be satisfactory.

\section{Results}

We conducted 2 X 2 analyses of variance with the basic needs, intrinsic motivation and academic performance as dependent variables and two independent variables: method of instruction (jigsaw classroom / cyclical rotation learning) and study topic (scanning electron microscope / microwave oven). The results are shown in Table 3. Depicted are the adjusted means and standard deviations (in brackets). For all variables, corresponding pretest measures were used as covariates.

[Insert Table 3 about here]

Basic needs and intrinsic motivation

With regard to the basic needs and the intrinsic motivation no significant interaction between method of instruction and topic appeared (see Table 3, right column). From that reason we aggregate across both study topics. The results are depicted in Figure 2.

[Insert Figure 2 about here] 
As expected from the theoretical reasoning, with respect to the basic needs both methods have different strengths and weaknesses: While the jigsaw classroom is favourable concerning the feeling of competence, the students feel more autonomous working in the cyclical rotation condition. Following the proposal of Cohen (1988), the range of the effect sizes run from small (competence, $d=.24$ ) to medium (autonomy, $\mathrm{d}=.39$ ). We found no difference with regard to the social relatedness. Thus, the hypotheses $1 \mathrm{a}$ - c are supported. Additionally, according to hypothesis 2 the intrinsic motivation was nearly equal in both settings. In the light of the self-determination theory this finding might be interpreted as a counteracting effect: the higher experience of competence in the jigsaw classroom is balanced by a higher feeling of autonomy in the cyclical rotation setting, leading to equal intrinsic motivation. This view is supported by a path analysis shown in Figure 3. The experience of competence as well as autonomy mediate from method of instruction (jigsaw and cyclical rotation learning, respectively) to intrinsic motivation. Furthermore, the path analysis shows that social relatedness did not play a crucial rule for motivation.

[Insert Figure 3 about here]

\section{Academic Performance}

Concerning the question, which method of instruction is more favourable with regard to performance, we found that it depends on whether the electron microscope or the microwave oven was used as the study topic: students working 
in cyclical rotation groups outperformed the jigsaw groups when learning the electron microscope. But when the microwave oven was taught, the jigsaw groups performed slightly better (Table 3). Thus the interaction between method of instruction and study-topic was significant. The question arises, what causes this interaction. A first hint is given by Figure 4: For the jigsaw classroom condition, academic performance is divided into expert performance (students' score on that part of the test that covered the segment of the learning material assigned to the student) and tutored performance (the students' score on that part of the test that tested segments a student had learned about from fellow group members).

\section{[Insert Figure 4 about here]}

The better performance of the jigsaw groups in the microwave oven learning unit is due to the fact, that the tutored performance is equal to the performance in the cyclical rotation setting. This is not the case in the electron microscopy learning unit. We examine two possible assumptions that might play a crucial role for the latter result:

1. If the microwave oven learning unit is more easy to comprehend than the electron microscope, this should lead to an enhanced feeling of competence compared to that experienced in the electron microscope unit. But the difference in experiencing competence between both topics is not significant (see Table 3). 
2. The students are substantially more interested in the microwave oven learning unit $(\mathrm{t}(207)=3.42 ; \mathrm{p}=.00)$. This was assessed with a 19 item scale ('Interestingness’) provided by Hoffmann et al. (1997). The reliability of the scale is $\alpha=.91$. The effect size is estimated to be $d=.48$, that is, a medium effect.

In order to test whether the interestingness can be regarded as a mediator between topic (that is the scanning electron microscope and the microwave oven, respectively) and achievement in the tutored segments (cf. Figure 5), we follow the proposal by Baron \& Kenny (1986).

[Insert Figure 5 about here]

They recommend to accomplish a series of three regression equations (unstandardized regression coefficients, standard errors in brackets):

1. Tutored performance is used as the criterion and topic as the predictor ${ }^{2}$ : $\mathrm{c}=.082(.030) ; \mathrm{p}=.008$

2. Interestingness is used as the criterion variable and topic as the predictor: $\mathrm{a}=.315$ (.091); $\mathrm{p}=.001$

3. The tutored performance is used as the criterion variable and interestingness as well as topic as predictors: $\mathrm{b}=.057(.023) ; \mathrm{p}=.016$ and $\mathrm{c}^{\prime}=.064(.031)$; $\mathrm{p}=.039$.

\footnotetext{
${ }^{2}$ Additionally, the pretest measure for performance was included as predictor in all analyses.
} 
That is, when controlling for the mediator, the beta-weight from topic to performance is decreased from $.082 * *$ to $.064 *$. Running the SOBEL-Test as proposed by Preacher \& Hayes (2004) it is shown that this decrease is statistically significant on a .05 level $^{3}$. Following Baron \& Kenny, the link from topic over interestingness to tutored performance thus is a partial mediator.

\section{Discussion}

On the basis of Deci and Ryans self-determination theory we assessed two small-group settings, the jigsaw classroom and cyclical rotation learning. Both methods show characteristic advantages particularly with regard to its capabilities in fostering the experience of autonomy and competence. On the one hand, the students feel less autonomous when working in the jigsaw classroom. The benefits of the cyclical rotation method with regard to the experience of autonomy might result from the more open structure. For example, in the jigsaw classroom a deadline for working in the expert groups is defined. This might derogate the experience of autonomy. On the other hand, the teaching expectancy in the expert groups might stimulate an intensive interaction with one segment of the topic, what should favour the experience of competence. This is particularly interesting in light of the frequently espoused position that teaching expectancy might lead to anxiety and thus a degradation of intrinsic motivation: most of the students participating in the study seem to be familiar with giving explanations to their peers. Furthermore, this is accompagnied by a pronounced feeling of relatedness.

\footnotetext{
${ }^{3}$ Calculated online from http://www.psych.ku.edu/preacher/sobel/sobel.htm (Retrieved February 15th, 2007).
} 
Due to the similar structure of both learning methods no noticeable difference can be observed regarding social relatedness. Concerning the instrinsic motivation no appreciable difference is observed. As suggested by a path analysis this comes about because two opposing factors, autonomy and competence, balance each other. This is in accordance with the self-determination theory which states, that the experience of competence as well as autonomy have to be fostered to enhance motivation (Deci \& Ryan, 2000). Furthermore the path analysis shows that the social relatedness plays no significant role for the intrinsic motivation. This point is discussed controversially in the literature.

Regarding academic performance no main effect of method of instruction was found when aggregating across both study topics electron microscope and microwave oven. This is in accordance with the results from a study conducted by Hidi et al. (1998): after initial classroom instruction the students worked in a science center in small group settings. The authors did not find differences in posttest academic performance between jigsaw and the cyclical rotation method. In our study a significant interaction indicates that performance depends on the study topic (cf. Table 3). With respect to the unit 'scanning electron microscope', the cyclical rotation method outperformed the jigsaw classroom, whereas an opposed trend is observed with regard to the microwave oven learning unit. This is due to the better results in the part of the test covering areas of the material that jigsaw participants had been taught by fellow group members. We elucidated the interestingness of the study topics as a partial mediator between method of 
instruction and performance: a higher interestingness might lead to an enhanced arousal during instruction in the jigsaw groups. Furthermore, an appealing study topic should foster a more intensive study of the learning material at home. Nevertheless, it seems clear that the observed discrepancy cannot be ascribed to a single factor. This question needs further research.

Due to the design of the study, the observed effects can not clearly be traced back to one of the factors teaching expectancy, giving explanations or resource interdependence. In a subsequent study these factors are investigated separately, what should explain their relative meaningfulness.

With regard to the jigsaw method further research is needed on how to improve the knowledge transmission from the experts to novices. It probably might be helpful if future research would focus stronger on investigating mediating links between the method of instruction and learning outcomes. This will give further insight into specific benefits and drawbacks of teaching methods and helps to abandon the fruitless discussion about "the best method".

The results of the present study might give teachers valuable hints for the choice of the appropriate method, best suited to the teaching objectives. If the difficulty of the group task is well adapted to the students' cognitive level the jigsaw classroom is a powerful method in promoting the experience of competence, especially for students with below average physics related self-concept (cf. also Hänze \& Berger, 2007).

Acknowledgements

URL: http://mc.manuscriptcentral.com/tsed Email: editor_ijse@hotmail.co.uk 24 
The current research was supported by a grant from the Deutsche Forschungsgemeinschaft (DFG) allocated to both authors (HA 3509/1-1).

\section{References}

Antil, L. R., Jenkins, J. R., Wayne, S. K., \& Vadasy, P. F. (1998). Cooperative learning: Prevalence, conceptualizations, and the relation between research and practice. American Educational Research Journal, 35(3), 419-454.

Aronson, E. (1978). The jigsaw classroom. Beverly Hills, CA: Sage.

Aronson, E. (2002). Building empathy, compassion, and achievement in the jigsaw classroom. In J. Aronson (Ed.), Improving academic achievement. Impact of psychological factors on education (pp. 209-225). San Diego, CA: Academic Press.

Baron, R. M., \& Kenny, D. A. (1986). The moderator-mediator variable distinction in social psychological research: Conceptual, strategic, and statistical considerations. Journal of Personality and Social Psychology, 51(6), 1173-1182.

Benware, C. A., \& Deci, E. L. (1984). Quality of learning with an active versus passive motivational set. American Educational Research Journal, 21 (4), 755765.

Berger, R., \& Hänze, M. (2004). Das Gruppenpuzzle im Physikunterricht der Sekundarstufe II - Einfluss auf Motivation, Lernen und Leistung. Zeitschrift für Didaktik der Naturwissenschaften, 10, 205-219 
Buchs, C., Butera, F., \& Mugny, G. (2004). Resource interdependence, student interactions and performance in cooperative learning. Educational Psychology, 24 (3), 291-314.

Cohen, E. G. (1994). Restructuring the classroom: Conditions for productive small groups. Review of Educational Research, 64 (1), 1-35.

Cohen, J. (1988). Statistical power analysis for the behavioral sciences (2nd ed.). Hillsdale, NJ: Lawrence Earlbaum Associates.

Dansereau, D. F. (1988). Cooperative Learning Strategies. In C. E. Weinstein, E. T. Goetz, \& P. A. Alexander (Eds.), Learning and Study Strategies (pp. 103120). San Diego: Academic Press.

Deci, E. L., \& Ryan, R. M. (2000). The 'what' and 'why’ of goal pursuits: Human needs and the self-determination of behavior. Psychological Inquiry, 11, 227268.

Gillies, R. M. (2003). Structuring cooperative group work in classrooms. International Journal of Educational Research, 39, 35-49.

Goldstein, J. I., Newbury, D.E., Echlin, P., Joy, D. C., Romig, A. D., Lyman, C. E., Fiori, C., \& Lifshin, E. (1992). Scanning electron microscopy and x-ray microanalysis (2nd ed.). New York: Plenum Press.

Hänze, M., \& Berger, R. (2007). Cooperative learning, motivational effects and student characteristics: An experimental study comparing cooperative learning and direct instruction in 12th grade physics classes. Learning and Instruction, 17, 29-41. 
Häussler, P. (1987). Measuring students’ interest in physics - design and results of a cross-sectional study in the Federal Republic of Germany. International Journal of Science Education, 9 (1), 79-92.

Hidi, S., Weiss, J., Berndorff, D., \& Nolan, J. (1998). The role of gender, instruction and a cooperative learning technique in science education across formal and informal settings. In L. Hoffmann, A. Krapp, K.A. Renninger, \& J. Baumert (Eds.), Interest and Learning (pp. 215-227). Kiel, Germany: IPN.

Hoffmann, L., Häußler, P., \& Peters-Haft, (1997). An den Interessen von Mädchen und Jungen orientierter Physikunterricht. [Physics education oriented to the interests of girls and boys]. Kiel, Germany: IPN.

Huber, G. L. (2003). Processes of decision-making in small learning groups. Learning and Instruction, 13, 255-269.

Krapp, A. (2002). Structural and dynamic aspects of interest development: theoretical considerations from an ontogenetic perspective. Learning and Instruction, 12, 383-409.

Leisen, J. (2004). Einheitliche Prüfungsanforderungen Physik. Der mathematische und naturwissenschaftliche Unterricht 57 (3), 155-159.

Preacher, K. J., \& Hayes, A. F. (2004). SPSS and SAS procedures for estimating indirect effects in simple mediation models. Behavior Research Methods, Instruments, \& Computers, 36 (4), 717-731.

Prenzel, M., Duit, R., Euler, M., Lehrke, M., \& Seidel, T. (2001). Erhebungs- und Auswertungsverfahren des DFG-Projekts 'Lehr-Lern-Prozesse im Physikunterricht - eine Videostudie’. Kiel, Germany: IPN. 
Prenzel, M., Eitel, F., Holzbach, R., Schoenheinz, R.-J., \& Schweiberer, L. (1993). Lernmotivation im studentischen Unterricht in der Chirurgie. [Motivation to learn in surgery courses]. Zeitschrift für Pädagogische Psychologie, 7 (2/3), 125-137.

Renkl, A. (1995). Learning for later teaching: an exploration of mediational links between teaching expectancy and learning results. Learning and Instruction, 5, 21-36.

Ryan, R. M., \& Deci, E. L. (2000). Intrinsic and extrinsic motivations: Classic definitions and new directions. Contemporary Educational Psychology, 25, 5467.

Simons, P. R. J. (1997). Definitions and theories of active learning. In D. Stern \& G. L. Huber (Eds.), Active learning for students and teachers. (pp. 19-39). Frankfurt, Germany: Peter Lang.

Slavin, R. E., Hurley, E. A., \& Chamberlain, A. (2003). Cooperative learning and achievement: Theory and research. In W. M. Reynolds, \& G. E. Miller (Eds.), Handbook of Psychology: Educational Psychology, Vol. 7 (pp. 177 -197). New York: Wiley.

Springer, L., Stanne, M. E., \& Donovan, S. S. (1999). Effects of small-group learning on undergraduates in science, mathematics, engineering, and technology: A meta-analysis. Review of Educational Research, 69 (1), 21-51.

Vallerand, R. J. (2000). Deci and Ryan's self-determination theory: A view from the hierarchical model of intrinsic and extrinsic motivation. Psychological Inquiry, 11, 312-318. 
1

2 3

\section{Table 2}

Results of the basic needs factor analysis

\begin{tabular}{llll} 
& Factor 'Social & Factor & Factor \\
& Relatedness' & 'Competence' & 'Autonomy' \\
\hline SR 1 & .89 & .15 & -.01 \\
SR 2 & .81 & .26 & .14 \\
C 1 & .18 & .91 & .11 \\
C 2 & .24 & .89 & .09 \\
A 1 & .06 & .08 & .82 \\
A 2 & .05 & .09 & .82 \\
\hline
\end{tabular}


Table 3

Basic needs, intrinsic motivation and academic performance as a function of method of instruction and study topic.

\begin{tabular}{|c|c|c|c|c|c|c|c|}
\hline & \multicolumn{2}{|c|}{$\begin{array}{c}\text { Electron } \\
\text { microscope }\end{array}$} & \multicolumn{2}{|c|}{ Microwave oven } & \multicolumn{3}{|c|}{ and F-values) } \\
\hline & $\begin{array}{l}\text { Jigsaw } \\
(n=128)\end{array}$ & $\begin{array}{l}\text { Cyclical } \\
\text { rotation } \\
(n=156)\end{array}$ & $\begin{array}{l}\text { Jigsaw } \\
(n=116)\end{array}$ & $\begin{array}{l}\text { Cyclical } \\
\text { rotation } \\
(n=100)\end{array}$ & Method & Topic & $\begin{array}{l}\text { Method } \\
\text { X Topic }\end{array}$ \\
\hline \multirow{2}{*}{ Autonomy } & 3.47 & 3.79 & 3.28 & 3.64 & $p=.00$ & $p=.03$ & $\mathrm{p}=.80$ \\
\hline & $(0.93)$ & $(0.74)$ & $(0.94)$ & $(0.73)$ & $F=17.8$ & $\mathrm{~F}=4.51$ & $\mathrm{~F}<1$ \\
\hline \multirow{2}{*}{ Competence } & 4.11 & 4.00 & 4.10 & 3.78 & $p=.00$ & $\mathrm{p}=.13$ & $\mathrm{p}=.16$ \\
\hline & $(0.81)$ & $(0.84)$ & $(0.83)$ & $(0.76)$ & $F=8.60$ & $\mathrm{~F}=2.34$ & $F=2.03$ \\
\hline Social & 4.19 & 4.22 & 4.24 & 4.16 & $\mathrm{p}=.71$ & $\mathrm{p}=.97$ & $\mathrm{p}=.46$ \\
\hline Relatedness & $(0.84)$ & $(0.78)$ & $(0.77)$ & $(0.84)$ & $\mathrm{F}<1$ & $\mathrm{~F}<1$ & $\mathrm{~F}<1$ \\
\hline Intrinsic & 3.43 & 3.45 & 3.34 & 3.54 & $\mathrm{p}=.13$ & $\mathrm{p}=.96$ & $\mathrm{p}=.19$ \\
\hline Motivation & $(0.79)$ & $(0.86)$ & $(0.79)$ & $(0.86)$ & $\mathrm{F}=2.28$ & $\mathrm{~F}<1$ & $F=1.73$ \\
\hline Academic & $49 \%$ & $56 \%$ & $54 \%$ & $51 \%$ & $\mathrm{p}=.31$ & & $p=.01$ \\
\hline Performance $^{\mathrm{a}}$ & $(23 \%)$ & $(26 \%)$ & $(21 \%)$ & $(22 \%)$ & $F=1.05$ & & $F=6.46$ \\
\hline
\end{tabular}

Note. ${ }^{\mathrm{a}}$ in percent of maximum score. The degree of freedom for all variables is $\mathrm{df}=(1 ; 443)$. 


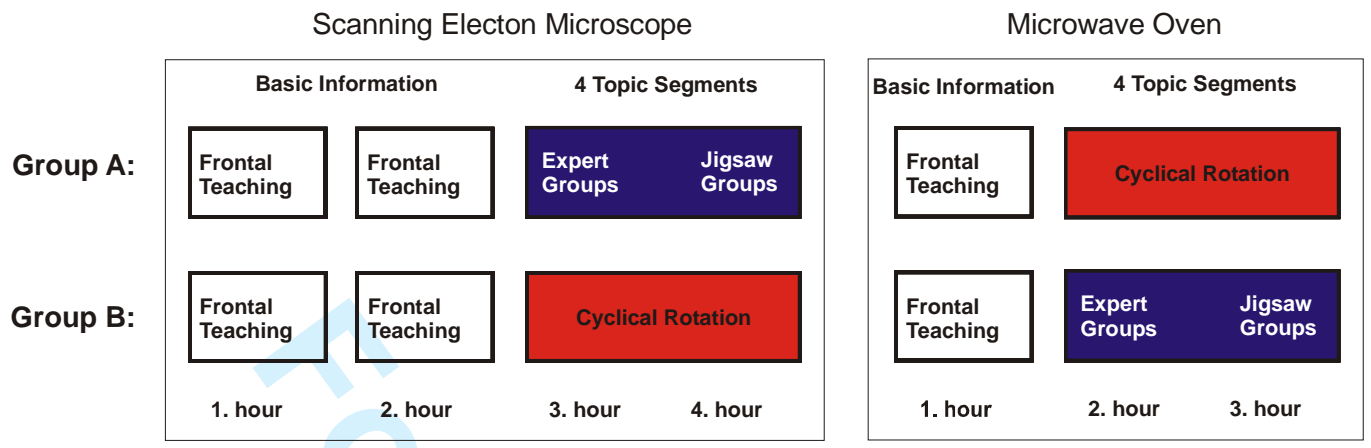

Figure 1. Design of the study.

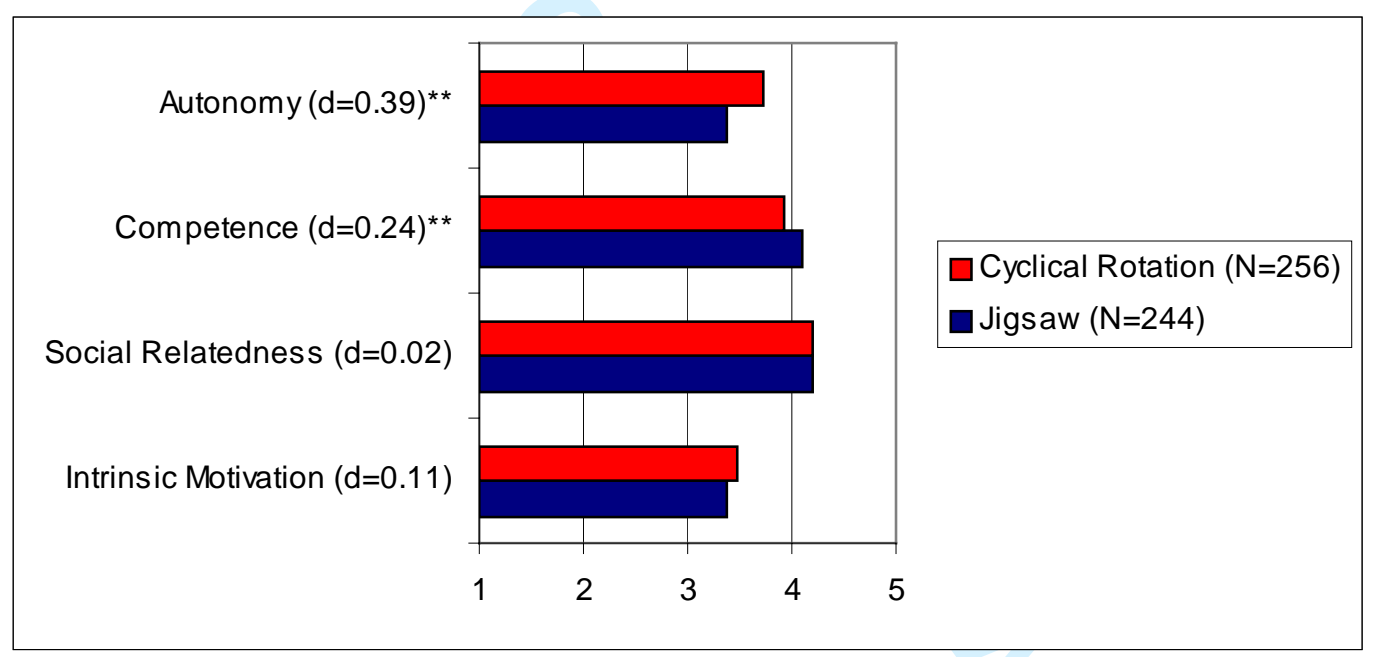

Figure 2. Adjusted means of the Basic Needs und intrinsic motivation aggregated across both topics. For all variables, corresponding pretest measures were used as covariates. The effect size (Cohen’s d) is depicted in brackets. $(* *:<.01 ; *:<.05)$. 


\section{Pretest Treatment Posttest}

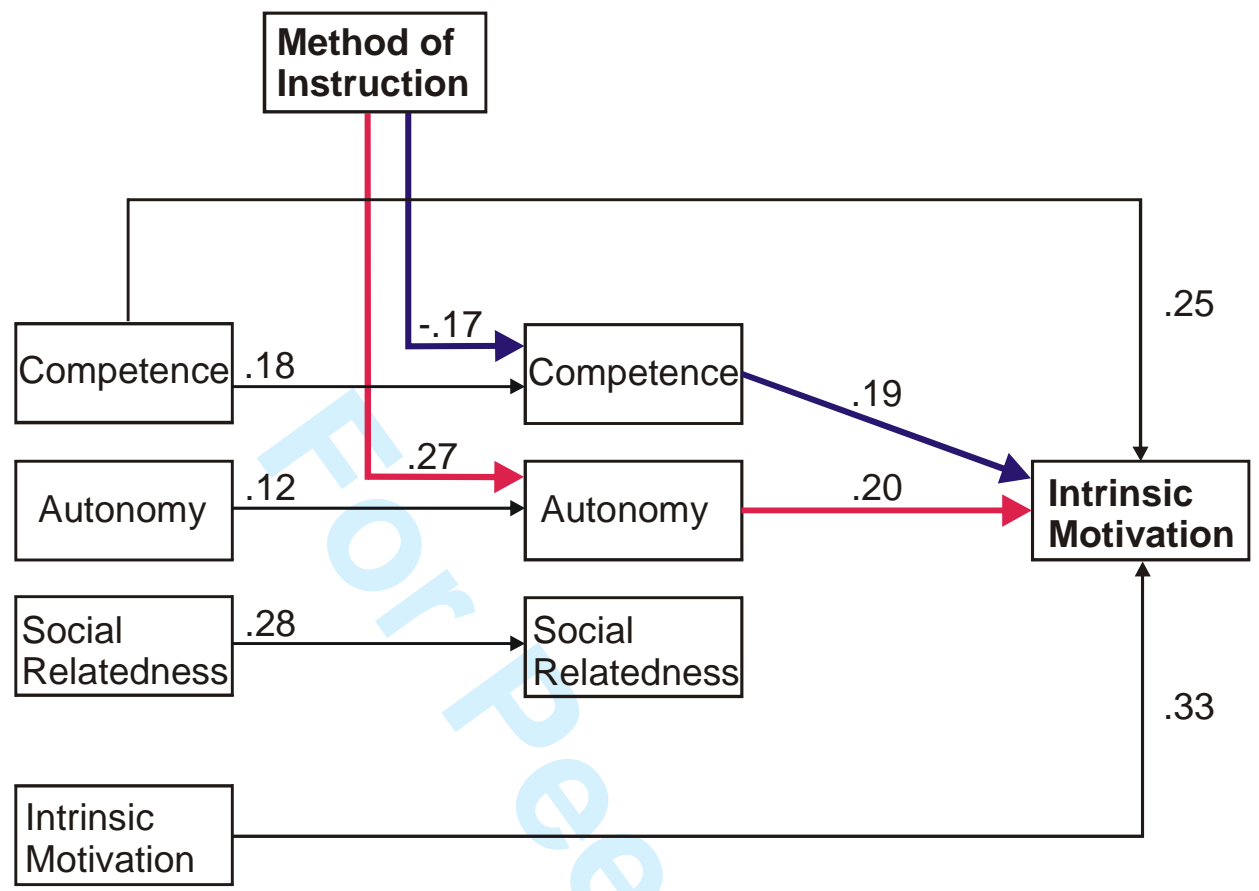

Figure 3. Path-analytic model: Influence of method of instruction on intrinsic motivation mediated by the basic needs. Jigsaw classroom and cyclical rotation are coded as 1 and 2, respectively. Only the significant paths are depicted. The results from the pretest measurement are included to control for preexperimental differences. $\left(N=375, \chi^{2}(1)=0.97\right.$, $\left.\mathrm{p}=.32, \mathrm{RMSEA}=0.0, R^{2}=.26\right)$. 
Figure 4. Performance in Percent of maximum score. The depicted means are adjusted by the pretest covariate.

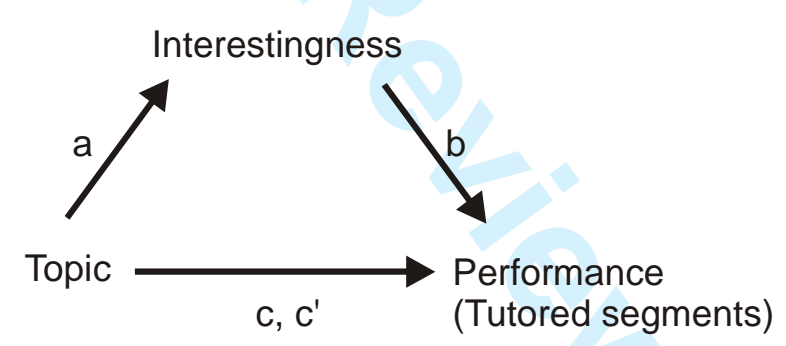

Figure 5. Model for testing the question if the interestingness is a mediator between topic and tutored performance. 